\title{
Cadaveric Length of Trachea in Bangladeshi Adult Male
}

Tahmina Begum ${ }^{1}$, Humaira Naushaba², Jahangir Alam ${ }^{3}$, Uttam Kumar Paul ${ }^{4}$, Afshan Jesmin Alim $^{5}$, Jesmin Akter ${ }^{6}$, Ruksana Ahmed ${ }^{7}$

\begin{abstract}
Context: Anatomical knowledge about length of trachea is essential for anesthetists, surgeons, radiologists \& sonologists. In anesthetic procedure, the knowledge of the length of trachea helps to select correct sizes of endotracheal tubes.
\end{abstract}

Study Design: A descriptive type of study.

Place and period of study: The study was carried out in the Department of Anatomy, Sir Salimullah Medical College, Dhaka, from July 2006 to June 2007.

Materials: 47 trachea of Bangladeshi adult male, age ranged from 20 to 58 years within 24 hours after death which were autopsied in the Department of Forensic Medicine of Sir Salimullah Medical College \& Dhaka Medical College, Dhaka.

Method: The collected samples were divided into four age groups, ranged from 20 to 58 years and comparative studies were done between different age groups.

Result: The length of trachea increased with advancing age. The values showed positive correlation with age \& statistically was highly significant $(P<0.001)$.

Conclusion: In the present study the length of the trachea increased with the increasing age. Further study with large sample size is required to make standard data for Bangladeshi adult male.

Key words: Trachea, Length.

\section{Introduction:}

The trachea, a tube of cartilage and fibromuscular membrane, about 10-11 cm long \& extends from the sixth cervical vertebra to the upper border of fifth thoracic vertebra ${ }^{1}$. The length varies with age ${ }^{2}$. It splits into right \& left main stem bronchi which enter the respective lungs \& progressively branch off throughout the entire organ, the tracheo bronchial tree ${ }^{3}$.

1. Lecturer, Department of Anatomy, Sir Salimullah Medical College, Dhaka.

2. Professor and Head of the Department of Anatomy, Sir Salimullah Medical College, Dhaka.

3. Assistant Professor, Department of Anatomy, Sir Salimullah Medical College, Dhaka.

4. Assistant Professor, Department of Anatomy, Sir Salimullah Medical College, Dhaka.

5. Assistant Professor, Department of Anatomy, Bangladesh Medical College, Dhaka.

6. Assistant Professor, Department of Anatomy, Ibrahim Medical College, Dhaka.

7. Lecturer, Department of Anatomy, Dhaka Medical College, Dhaka.

Correspondence: Dr. Tahmina Begum
The tracheo bronchial tree is the essential part of respiratory tract. It serves as a tubular system for conducting air into \& out of the alveoli of lung. In addition, it participates in humidification, temperature adjustment \& elimination of air born pollutants of inspired air 4 . Anatomical knowledge about the length of trachea is essential for anaesthetists for selecting anatomically designed cuff for endotracheal intubation ${ }^{5}$.

The present study was planned to establish our standard data and to compare the data with that of other countries.

\section{Materials and Methods:}

47 trachea of Bangladeshi adult male of different ages were selected for the present study. The samples were collected from unclaimed dead bodies autopsied in the Department of Forensic Medicine of Sir Salimullah Medical College \& Dhaka Medical College within 12 to 36 hours of death. World Health Organization (WHO) defined an 
adolescent as a person between $10 \& 19$ years of age. The present study was planned to collect samples from Bangladeshi adult male. So, the samples were collected from male $20 \&$ above 20 years of age.

The samples were washed gently \& thoroughly with running tap water $\&$ tagged properly bearing an identification number $\&$ age of the cadaver. Then these were kept in $10 \%$ formol saline solution for fixation \& preservation. The formol fixed sample was washed properly \& a careful dissection was done to expose the desired structures.

\section{Grouping of the samples:}

The samples were divided into four age groups; Group A (20-29 years), Group B (30-39 years), Group C (40-49 years) and Group D (50-59 years). [Table-I].

Table-I

Age distribution in different study groups

\begin{tabular}{lcc}
\hline Study groups & $\begin{array}{c}\text { Age range } \\
\text { (in years) }\end{array}$ & $\begin{array}{c}\text { No. of samples } \\
(\mathrm{n}=47)\end{array}$ \\
\hline A & $20-29$ & 16 \\
B & $30-39$ & 16 \\
C & $40-49$ & 08 \\
D & $50-59$ & 07 \\
\hline
\end{tabular}

Procedure of the study:

Measurement of length of trachea:

The length of trachea was measured in $\mathrm{cm}$ by a measuring tape from the lower border of cricoid cartilage to the lower border of carina in midline ${ }^{6}$. (Fig-I).

\section{Observation and Result:}

In the study, the mean lengths of the trachea were $8.73 \pm 0.21 \mathrm{~cm}$ in Group A, $9.530 .46 \mathrm{~cm}$ in Group $B, 9.63 \pm 0.23 \mathrm{~cm}$ in Group C \& $9.79 \pm 0.39 \mathrm{~cm}$ in Group D. (Table-II \& Fig-2).

Statistical analysis showed positive correlation ( $r=$ +0.759 ) between age \& length of trachea $\&$ it was highly significant $(P<0.001)$. (Fig-3).

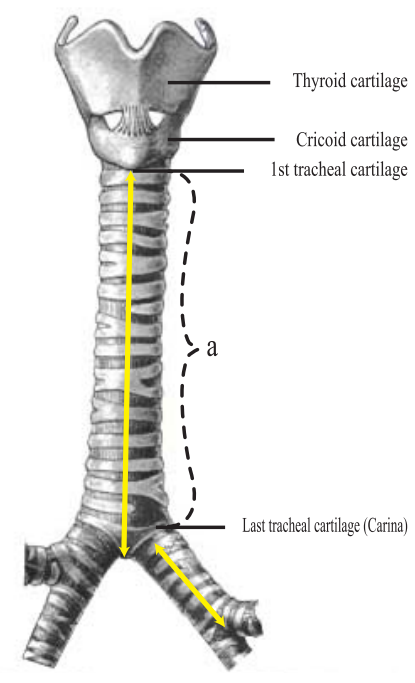

Fig.-1: Part of larynx, trachea and primary ronchi, showing the Measurement of the length of trachea

Table-II

Length of trachea in different study groups

\begin{tabular}{|c|c|c|c|}
\hline \multirow{2}{*}{\multicolumn{2}{|c|}{ Groups }} & $\mathrm{n}$ & Length in $\mathrm{cm}$ \\
\hline & & & Mean $\pm S D$ \\
\hline \multicolumn{2}{|l|}{$A$} & 16 & $\begin{array}{c}8.73 \pm 0.21 \\
(8.50-9.10)\end{array}$ \\
\hline \multicolumn{2}{|l|}{ B } & $\begin{array}{c}16 \\
(9.00-10.50)\end{array}$ & $9.53 \pm 0.46$ \\
\hline \multicolumn{2}{|l|}{ C } & 8 & $\begin{array}{c}9.63 \pm 0.23 \\
(9.50-10.00)\end{array}$ \\
\hline \multicolumn{2}{|l|}{ D } & $\begin{array}{c}7 \\
(9.50-10.50)\end{array}$ & $9.79 \pm 0.39$ \\
\hline \multicolumn{2}{|c|}{ Groups } & $P$ value & \\
\hline \multicolumn{2}{|l|}{$A$ vs $B$} & $<0.001^{\star \star \star}$ & \\
\hline \multicolumn{2}{|l|}{ A vs C } & $<0.001^{\star \star \star}$ & \\
\hline \multicolumn{2}{|l|}{$A$ vs $D$} & $<0.001^{\star * *}$ & \\
\hline \multicolumn{2}{|l|}{ B vs C } & $>0.50 \mathrm{~ns}$ & \\
\hline \multirow{2}{*}{\multicolumn{2}{|c|}{$\begin{array}{l}\text { B vs D } \\
\text { C vs D }\end{array}$}} & $>0.10 \mathrm{~ns}$ & \\
\hline & & $>0.10 \mathrm{~ns}$ & \\
\hline Group & $A$ & Age $20-29$ years & \\
\hline \multicolumn{2}{|c|}{ Group } & Age $30-39$ years & \\
\hline \multirow{2}{*}{$\begin{array}{l}\text { Group } \\
\text { Group }\end{array}$} & C & Age $40-49$ years & \\
\hline & $\mathrm{D}$ & Age $50-59$ years & \\
\hline \multicolumn{4}{|c|}{$\begin{array}{l}\text { Figures in parentheses indicate range. Statistica } \\
\text { analysis was done by ANOVA (multiple } \\
\text { comparison), ns }=\text { not significant, } * *=\text { significan }\end{array}$} \\
\hline
\end{tabular}




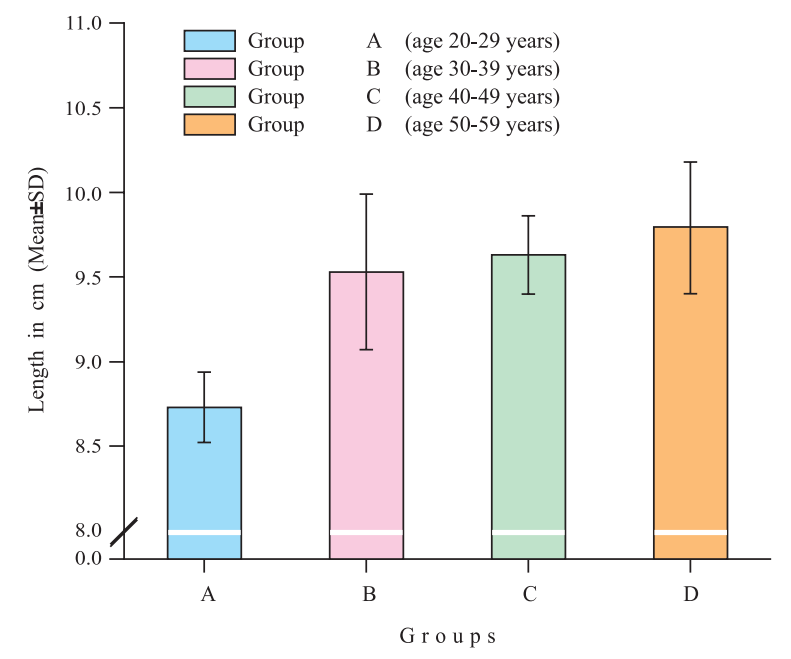

Fig.-2: Length of trachea in different study groups

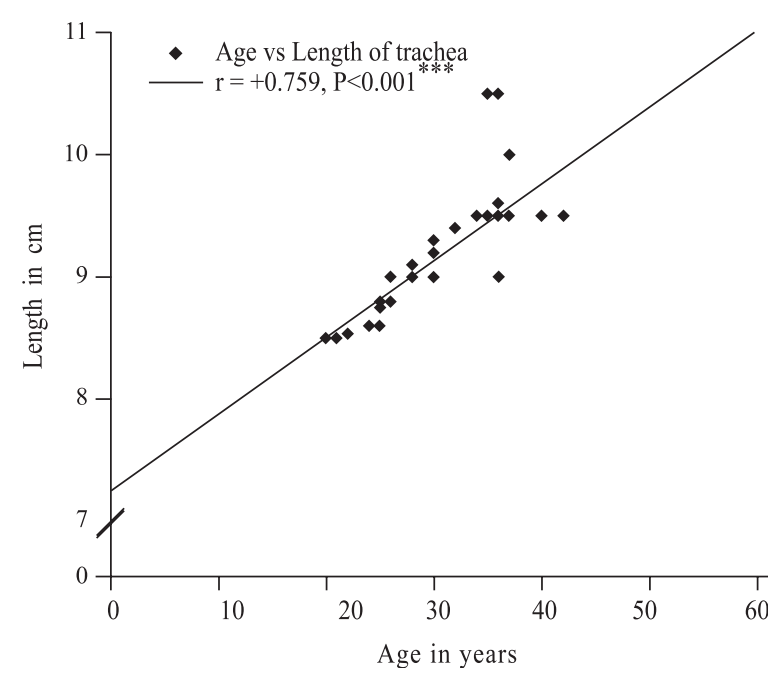

Fig.-3: Relationship between age and length of trachea

\section{Discussion:}

The present work was carried out on 47 trachea of autopsied Bangladeshi adult male. The result showed similarity as well as dissimilarity with other studies. The values were lower than those described by different western authors e.g. Shah $(2005)^{1}$, Snell $(2004)^{7}$, Allen $(2003)^{2}$, Thibodean \& Patton $(2003)^{8}$, Sinnatamby (1999) ${ }^{9}$ and Ellis \& Feldman $(1993)^{10}$. The racial and fixation factors may be responsible for the lower values of the present study. The findings were similar with that of Harjeet \& Indarjit (2000) ${ }^{11}$. The values were higher than those were reported by Narayan (2005) $)^{12}$ and Yousuf $(1996)^{13}$. Their study included some adolescents which acted as the lowering effect of their values.

\section{References:}

1. Johnson D, Shah P, Wigley C, Collins P. Thorax. In : Standring S, Ellis H, Healy JC, Johnson D, Williams A, Collins $P$ et al., editors. Gray's Anatomy. 39th ed. London : Elsevier Churchill Livingstone; 2005. p.105762, 1075-8.

2. Allen MS. Surgical anatomy of the trachea. Chest Surg Clin N Am 2003; 13 : 191-9.

3. Sitemap. 2006. Available at: http://www. ivyrose.co.uk/Topics/Respiratory Tracheobronchial_Tree.htm.

4. Phalen RF, Oldham MJ. Tracheobronchial airway structure as revealed by casting techniques. JAM REV RESPIR DIS 1983; 128 : S1-S4.

5. Mackenzie CF, McAslan TC, Shin B, Schellinger D, Helrich M. The shape of the human adult trachea. Anaesthesiology 1978; 49 (1): 48-50.

6. Butz RO. Length and cross section growth patterns in the human trachea. Pediatrics 1968 ; 42 (2) : 336-41.

7. Snell RS. Clinical anatomy. 7th ed. Baltimore : Lippincott Williams and Wilkins; 2004. p. 82.

8. Thibodeau GA, Patton KT. Anatomy and physiology. 5th ed. St. Louis : Mosby, Inc; 2003. p. 693-700.

9. Sinnatamby CS. Last's anatomy: regional and applied. 10th ed. Edinburgh: Churchill Livingstone; 1999. p. 187-8.

10. Ellis $\mathrm{H}$, Feldman $\mathrm{S}$. Anatomy for anesthetists. 6th ed. Oxford: Blackwell Scientific Publications, Inc; 1993. p. 46, 51.

11. Harjeet, Indarjit. Dimensions and shape of the trachea in the neonates, children and adults in northwest India. Indian Mes Res 2000; $112(7): 27-33$.

12. Saha NC. Gross and histomorphological study of human postmortem trachea and principal bronchi in Bangladeshi people [thesis]. Dhaka : University of Dhaka; 2005.

13. Yousuf BMA. Gross and histomorphological study of the tracheobronchial tree in Bangladeshi males [thesis]. Dhaka: University of Dhaka; 1996. 